\title{
Application of Freshly Collected Amniotic Membrane and Amniotic Fluid in Arthritis and Wound Healing
}

\author{
Niranjan Bhattacharya ${ }^{1 *}$, Priyodarshi Sengupta ${ }^{2 *}$ and Akash Bhattacharya ${ }^{2}$ \\ ${ }^{1}$ Head of the Department of Regenerative Medicine and Translational Science, Dr. Subhas Mukherjee Chair Professor, Director General, \\ Cord Blood Bank, Calcutta School of Tropical Medicine, India \\ ${ }^{2}$ Research Associate, Department of Regenerative Medicine and Translational Science, Calcutta School of Tropical Medicine, India
}

\section{Article Info}

\section{*Corresponding authors: \\ Niranjan Bhattacharya \\ Head, Department of Regenerative Medicine and Translational Science Calcutta School of Tropical Medicine Director General of Cord Blood Bank Calcutta School of Tropical Medicine India \\ Tel: +919830038158 \\ E-mail: sanjuktaniranjan@gmail.com}

\section{Priyodarshi Sengupta}

Department of Regenerative Medicine and Translational Science,

Calcutta School of Tropical Medicine Email: priyosengupta85@gmail.com

\section{Received: May 29, 2018 \\ Accepted: June 14, 2018 \\ Published: June 22, 2018}

Citation: Bhattacharya $N$, Sengupta $P$, Bhattacharya A. Application of Freshly Collected Amniotic Membrane and Amniotic Fluid in Arthritis and Wound Healing. Madridge J AIDS. 2018; 2(1): 38-41.

doi: $10.18689 / \mathrm{mja}-1000107$

Copyright: @ 2018 The Author(s). This work is licensed under a Creative Commons Attribution 4.0 International License, which permits unrestricted use, distribution, and reproduction in any medium, provided the original work is properly cited.

Published by Madridge Publishers

\begin{abstract}
The placenta is an important blood-placental barrier organ that plays an important part during the time of pregnancy by allowing the selective exchange of molecules and gases. It also helps in the removal of the fetal waste materials. The amniotic membranes of the placenta have been successfully used in burn and chronic non-healing ulcer dressings. Like cord blood, the placenta is also thrown away as a biological hazard in many countries without understanding its true potentialities. Clinical application of the dry and dehydrated human amniotic membrane (dHAM), chemically and thermally processed amniotic membranes has been used for closure and protection of wounds against infection for some time. However, since 1999, Bhattacharya et al., freshly collected amniotic membranes have been also successfully used for treating burn and other non-healing ulcer patients. The main advantage of this method is that as it is freshly collected, and not artificially processed or parched, its cellular components, growth factors, cytokines all remain intact and together they act as a superior biological dressing for the healing of wounds and ulcers including as a biological scaffold. Freshly collected amniotic membrane is another application of cell therapy using pregnancy specific biological substances. Amniotic fluid like amniotic membrane is also a biological substance having superior cell therapy properties and can be often used in regenerative medicine for clinical applications due to its high content of amniocytes, amniotic fluidderived stem cells, and growth factors.
\end{abstract}

Keywords: Amniotic membrane; Amniotic fluid; Placenta; Regenerative medicine.

\section{Introduction}

During the time of pregnancy, the placenta plays an important role in providing a barrier that allows the selective exchange of molecules and cells between the mother and the fetus without compromising the integrity of the fetal development. It also helps in the fetal circulation and removal of fetal waste materials. The placenta with the amniotic membrane, amniotic fluid, the placental cord and the fetal umbilical cord blood can be considered as pregnancy specific biological substances as they appear during the time of pregnancy to support the process of pregnancy and fetal development. These pregnancy specific biological substances have immense cell therapy applications in regenerative medicine to treat non-healing ulcers at the backdrop of leprosy, burn and leprosy wounds, and nonhealing ulcers due to trauma or diabetes. Still, now, pregnancy-specific biological substances are thrown away in the trash or incinerators without even realizing their tremendous potential in clinical science. The advantages of using pregnancy specific biological substances in regenerative medicine are immense. They are easy to collect and can be collected by any gynecologist or a trained person. Secondly, these biological substances are rich in progenitor 
and stem cells, cytokines, growth factors, and anti-inflammatory properties that aid the process of healing through repair and regeneration of the lost tissue and their functions.

The clinical application of dry and dehydrated human amniotic membrane (dHAM) or chemically, thermally processed amniotic membrane is not new and has been in clinical set up since the last century roughly. Most of the amniotic membranes used in such cases are processed and modified. The primary objective of such processed biological membranes is to protect the infected area of the wound by preventing exudation and re-epithelialization. Since 1999, Bhattacharya et al., has developed the method of the application of freshly collected amniotic membrane, properly screened for HIV-I, II, Hepatitis-B, C, CMV, Syphilis, malaria and other infectious diseases in more than 100 cases of patients suffering from burn injuries, leprosy with success.

\section{Structure and Cellular components of the Amniotic Membrane}

The amniotic membrane grossly consists of three important layers [1]. The innermost translucent layer covering the embryo or the amnion layer which lines the amniotic cavity along with the amniotic fluid. This amnion layer is rich in mesenchymal stromal cells, amniotic epithelial cells, embryonal like stem cells, and progenitor cells. The amnion and the chorion both have a basement membrane and a stromal layer [1], [2]. The second or middle rich collagen connective tissue layer which remains connected with the outer collagen-rich reticular chorionic layer [2], [3].

In general, the amniotic membrane is a rich source for progenitor, fetal, multipotent and even pluripotent like stem cells. The epithelial layer of the amniotic membrane contains the amniotic epithelial stem cells which participate in the process of wound healing and re-epithelialization. Presence of Collagen IV, V, and VII, fibronectin, proteoglycans, glycosaminoglycans, laminins and fibroblasts in the amniotic membrane helps in providing strength and tensile, mechanical support and acts as a scaffold for cellular migration to the wound area [1]. The chances of graft versus host reaction in amniotic membrane cell therapy is also low due to the downregulation of $H L A-A, B, C, D R$ in human amniotic epithelial cells and an increased suppression of neovascularization [4]. The presence of matrix metalloproteinases and their inhibitors along with growth factors helps in maintaining the balance between normal and excessive growth [1]. Different growth factors like FGF, PDGF, EGF, TGF- $\beta$ further promotes the method of healing including the anti-inflammatory molecules.

\section{Amniotic Fluid}

Another important component of the pregnancy-specific biological substances is the amniotic fluid. One of the most important properties of the amniotic fluid during pregnancy is to wash the vaginal canal before the birth of the baby and destroy any pathogenic environment [4]. The amniotic fluid is normally considered to be sterile and bactericidal in nature
[4]. The amniocytes are important cellular components of the amniotic fluid which harbors a large pool of self-renewal cells, predominantly fetal in nature and express pluripotent stem cell markers like SSEA-1, 3, 4, TRA-1-60, TRA-1-81 [5]. The cells expressing these markers might be considered as equivalent to embryonic and induced pluripotent stem cells but more characterization studies are still required [6], [7], [8], [9]. Studies have shown that the nature of these embryoniclike stem cells have a complex molecular behavior, and has the ability to express all the three germ layers [10].

Like embryonic stem cells, these amniocytes also have a high proliferative rate in vitro, and formation of teratomas or tumors have not been reported yet [11], [12]. The other important stem cell component of the amniotic fluid is the amniotic fluid-derived stem cells which can grow even without the feeder layers. Under in vitro conditions, the self-renewal or the doubling capacity of these cells have been observed to be quite high [14], [15]. These like amniocytes also do not form tumors [13], [14].

\section{Mechanism of Wound Healing by freshly collected Amniotic Membrane}

Wound healing itself is a very complicated biological phenomenon. It is generally accompanied by three stages which are i. inflammation, ii. Proliferation and iii. maturation with the release of cytokines, growth factors and stem cells [15]. Amniotic membrane has some distinct advantage due to which it can be considered as a superior wound healing model. Amniotic membrane can rapidly adhere to the wound bed, can maintain a balance between the process of angiogenesis and control of mesenchymal stem cells and synthesis of MMP's and their inhibitors such as TIMP's. This process facilitates the third stage which helps in reepithelialization of the wound surface because of the presence of amniotic epithelial cells. Lastly, amniotic membrane is thought to play a role in inhibiting the synthesis of proteases, PMN filtration, and secretion of growth factors from the donor fibroblast cells [1].

\section{Amniotic Membrane (AM), Amniotic Fluid (AF) \& Cell Therapy}

Applications of amniotic fluid and amniotic membrane in myocardial infarcted rats have shown that stem cells derived from AM and AF can improve cardiac conditions [16], [17]. $A M$ and $A F$ derived stem cells have shown improved liver function with increased serum albumin levels after intravenous injection in animal models [18], [19]. 8 weeks engraftment of AM derived stem cells has also been reported in case of a hepatic cirrhosis model [20]. Decellularized AM has been used as a nerve conduit for improving peripheral nerve regeneration in animal models with reports of secretion of various neuro and brain-derived trophic factors promoting neuroregeneration of the central and peripheral nervous system [21], [22]. Human AM derived stem cells has shown to inhibit 
the deposition of collagen-induced rheumatoid arthritis by alleviating damage to joints with decreased level of NK cells and a lower arthritis index score [23].

\section{Application of Amniotic Membrane in Burn Patients}

Lancet reported that in India alone, there are incidents of 163,000 fire-related deaths, especially among young women mainly due to dowry related issues, kitchen accidents, domestic violence, self-immolation, and suicide [15], [24]. The mortality rate of burn patients can be multifactorial as it depends upon the percentage and the area of burn, type of burn with diabetes, hypothyroid and malnutrition as background diseases [4], [15].

Normally in diabetic burn patients, sepsis, anatomical and functional disintegration of the wound area are the primary causes of high mortality rate. A wound that has not healed for more than 3 months is often regarded as chronic wound [4]. Infections in such cases are a common problem and can be controlled by artificial skin substitutes having non-toxic, elastic, and good adherence property [4]. Affordability is a major issue in a developing country like India in such cases. Many of the skin grafts that are currently in use do not satisfy the criteria of the exchange of micro-nutrients, oxygen to prevent infection [4].

Hence, due to the presence of the above limitations, the first application of freshly collected, non processed, serologically screened for HIV-I, II, CMV, Malaria, Syphilis, Hepatitis- B \& C, VDRL, amniotic membrane was applied in 1999 by Bhattacharya et al., [4] 64 patients after following the inclusion/exclusion criteria (24 males and 40 females with age range between 10 years to 71 years) were enrolled for the study. All the patients had $26 \%$ to $\& 76 \%$ burn sustained either due to thermal or chemical burn injuries [4], [15]. Normal saline was used to wash and clear debris from the burn wound site followed by the sprinkling of amniotic fluid for its anti-microbial action [4]. Next, amniotic membrane was applied on the wound bed. The fetal or amnion side is applied in case of superficial and partial thickness burn injuries [4], [15]. This helps in the epithelialization process. The maternal or the chorionic part is applied for improving angiogenesis [4], [15]. Normal medication was continued in all the patients. Depending upon the level of infection, all the patients were given intravenous antibiotics and then changed to oral antibiotics later on. Diabetic patients were already on oral anti-diabetic therapy including insulin [4], [27]. Routine monitoring and follow up of the patients were conducted to investigate the presence of graft rejection in the form of foul smell, exudation or any other clinical and pathological symptoms [4]. Physiotherapy and rehabilitation was continued. Six months long term follow up studies showed no mortality with 6 patients showing the symptoms of keloid and hypertrophic scar tissue formation. Other patients reported normal. No observation of post leukoderma in any of the patients [4], [16]. 14 patients showed cases of hypo-pigmentation. This was resolved in further follow up studies with normal skin color and texture. 5 cases of pediatric burns were also successfully treated with freshly collected amniotic fluid and fetal skin by the same group [26].

\section{Application of Amniotic Membrane in Leprosy Patients}

Bhattacharya et al., similarly treated patients suffering from leprosy with gangrene by amniotic membrane [16]. Maggots were removed and the affected area was washed with normal saline to remove any debris. Next amniotic fluid was sprinkled in the wound area for 5 to $10 \mathrm{~min}$ [17]. All partial or superficial wounds were covered with the amniotic membrane [17]. All patients were provided with standard anti-leprosy drugs and 3 months and 6 months follow up study was conducted by the formation of granulation tissues and re-epithelialization [16].

\section{Amniotic Fluid Application in Osteoarthritis}

Osteoarthritis is a common knee problem in the elderly age group. It has a high morbidity rate with practically no cure. Current medications focus on the alleviation of the symptoms and reduce the load [25]. Bhattacharya et al., injected freshly collected amniotic fluid in 52 Osteoarthritis patients with age group between 39 to 82 years and who had not responded well to current standard treatment and have exhausted all options [26], [27]. The treatment was divided into 2 arms where one arm received amniotic fluid treatment and the other steroid treatment [26], [27]. The arm which received the treatment with amniotic fluid responded well and showed an overall improvement compared to the steroid treatment arm even after 2 months of treatment completion. This better therapeutic efficacy with amniotic fluid was observed till the $4^{\text {th }}$ month [26], [27]. Also, it was revealed in joint and non-joint effusion studies that amniotic fluid had a better and positive outcome compared to steroid arm [26], [27].

\section{Conclusion}

In 1999, the first attempt to heal non-healing ulcers, wounds, and osteoarthritis by freshly collected amniotic membrane and amniotic fluid was started successfully. The whole idea behind the application of freshly collected and fully screened amniotic membrane and fluid was because of the presence of potent progenitor cells, stem cells combined with growth factors and cytokines unlike other methods for application of amniotic membrane. Cases of minor number of graft rejections post amniotic membrane application accompanied with a foul odor due to the sloughing and rejection of the amniotic membrane by the host's immune system and presence of pseudomonas aeruginosin have been reported [28]. However, the whole process of the application of amniotic membrane to treat irreversible conditions has proved to be a very effective and successful one and more molecular studies are required to confirm the mechanism by which complex mechanisms like regeneration, repair, and healing occurs so effectively. 


\section{References}

1. Donald E. Fetterolf, Snyder RJ. Scientific and Clinical Support for the Use of Dehydrated Amniotic Membrane in Wound Management. Wounds. 2012; 24 (10): 299-307.

2. Dua HS, Jose A.P. Gomes, King AJ, Maharajan VS. The diagnostic and surgical technique. Survey of Ophthalmology. 2004; 49(1): 51-77

3. Bhattacharya N, Stubblefield P. Regenerative Medicine using Non-fetal sources of stem cells, A Massive wastage of the global resources. SpringerVerlag London Limited. 2015; 1: 4-5.

4. Bhattacharya N, Stubblefield P. Regenerative Medicine using Pregnancy specific biological substances, Use of Amniotic Membrane, Amniotic Fluid, and Placental dressing in Advanced Burn Patients. Springer-Verlag London Limited. 2009; 37: 383-393.

5. Bhattacharya N, Stubblefield P. Regenerative Medicine using Pregnancy specific biological substances, Amniotic fluid and placental stem cells, Anthony Atala. Springer-Verlag London Limited. 2009; 36: 375-380.

6. Moschidou D, Mukherjee S, Blundell MP, Drews K, Jones GN, et al. Valproic Acid Confers Functional Pluripotency to Human Amniotic Fluid Stem Cells in a Transgene-free Approach. Mol. Ther. 2012; 20(10): 1953-67. doi: 10.1038/mt.2012.117

7. Li C, Zhou J, Shi G, Ma Y, Yang Y, et al. Pluripotency can be rapidly and efficiently induced in human amniotic fluid-derived cells. Hum Mol Genet. 2009; 18: 4340-9. doi: $10.1093 / \mathrm{hmg} / \mathrm{ddp} 386$

8. Wolfrum $\mathrm{K}$, Wang $\mathrm{Y}$, Prigione A, Sperling $\mathrm{K}$, Lehrach $\mathrm{H}$, et al. The LARGE principle of cellular reprogramming: lost, acquired and retained gene expression in the foreskin and amniotic fluid-derived human iPS cells. PLoS One. 2010; 5: 13703. doi: 10.1371/journal.pone.0013703

9. Liu T, Zou G, Gao $Y$, Zhao X, Wang $H$, et al. High-Efficiency of Reprogramming CD34 (+) Cells Derived from Human Amniotic Fluid into Induced Pluripotent Stem Cells with Oct4. Stem cells and development. 2012; 21(12): 2322-32. doi: 10.1089/scd.2011.0715

10. Maguire CT, Demarest BL, Hill JT, Palmer JD, Brothman AR, Yost HJ, Condic $\mathrm{ML}$, et al. Genome-Wide Analysis Reveals the Unique Stem Cell Identity of Human Amniocytes. PLOS ONE. 2013; 8(1): 53372. doi: 10.1371/journal. pone. 0053372

11. De Coppi P, Bartsch G, Jr, Siddiqui MM, Xu T, Santos CC, et al. Isolation of amniotic stem cell lines with potential for therapy. Nat Biotechnol. 2007; 25: 100-6. doi: 10.1038/nbt1274

12. Prusa AR, Marton E, Rosner M, Bernaschek G, Hengstschläger M. Oct-4expressing cells in human amniotic fluid: a new source for stem cell research? Human Reproduction. 2003; 18(7): 1489-1493.

13. Cananzi M, Paolo De Coppi, CD117+ amniotic fluid stem cells, State of the art and future perspectives. Organogenesis. 2012; 8(3): 77-88. doi: 10.4161/org.22426.

14. Margit Rosner, Katharina Schipany, Bharanidharan Shanmugasundaram, GertLubec, and Markus Hengstschläger, Amniotic Fluid Stem Cells: Future Perspectives, Stem Cells International. 2012. doi: 10.1155/2012/741810

15. Bhattacharya N, Stubblefield P. Regenerative Medicine using Non-fetal sources of stem cells, Freshly collected Amniotic fluid and Amniotic membrane as dressing material for leprosy patients: A preliminary case report on an Experience with six cases. Springer-Verlag London Limited. 2015; 26: 257-260.
16. Fang $\mathrm{CH}$, Jin J, Joe JH, Song YS, So BI, Lim SM, Cheon GJ, Woo SK, Ra JC, Lee YY, Kim KS, et al. In vivo differentiation of human amniotic epithelial cells into cardiomyocyte -like cells and cell transplantation effect on myocardial infarction in rats: comparison with cord blood and adipose tissue derived mesenchymal stem cells. Cell Transplant. 2012; 21(8): 1687-96.

17. Wang YY, Fang N, Chen DX, Yu LM, Liu ZL, Wan X, et al. Human amnionderived mesenchymal stem cells engraftment and differentiate in rats with acute myocardial infarction. ZhongGuo Lao NianXueZaZhi. 2013; 4(33): 1583-6.

18. Gong LM, Fang N, Chen DX, Wan EH, Zhang T, Liu ZL, Yu LM, Zhao CH. ZhongGuoZuZhi Gong Cheng Yan Jiu Yu Lin Chuang Kang Fu. 2011; 15(36): 6709-12.

19. Zheng YB, Zhang $X H$, Huang ZL, Lin CS, Lai J, Gu YR, Lin BL, Xie DY, Xie SB, Peng L, Gao ZL, et al. Amniotic-fluid-derived mesenchymal stem cells overexpressing interleukin-1 receptor antagonist improve fulminant hepatic failure. PLoS One. 2012; 7(7): 41392. doi: 10.1371/journal. pone.0041392

20. Zhang $D$, Jiang $M$, Miao D. Transplanted human amniotic membranederived mesenchymal stem cells ameliorate carbon tetrachloride-induced liver cirrhosis in a mouse. PLoS One. 2011; 6(2): 16789. doi: 10.1371/ journal.pone.0016789

21. Banerjee $A$, Nürnberger $S$, Hennerbichler $S$, Riedl $S$, Schuh $C M$, Hacobian A, Teuschl A, Eibl J, Redl H, Wolbank $S$, et al. In toto differentiation of human amniotic membrane towards the Schwann cell lineage. Cell Tissue Bank. 2014; 15(2): 227-39. doi: 10.1007/s10561-013-9401-1

22. Liang $H$, Liang $P$, Gao A, Qi Q, Liu E, Wu J, Xu X, et al. A new composite matrix bridging both stumps of spinal cord transection in rats to promote recovery of motor function. Zhongguo Xiu Fu Chong JianWai Ke Za Zhi. 2009; 23(11):1376-81.

23. Xiao Y, Fang N, Chen DX, Yu LM, Zhang T, Zhao $\mathrm{CH}$, et al. Therapeutic effect and immunological regulation of human amniotic mesenchymal stem cells on the rat with collagen-induced arthritis. Man Yi XueZaZhi. 2013; 29(6): 461-6.

24. Sanghavi P, Bhalla K, Das V. Fire Related Deaths in India in2001 A Retrospective Analysis of Data. Lancet. 2009; 373(9671): 1282-88. doi: 10.1016/S0140-6736(09)60235-X

25. Ref: Royal College of General Practitioners. Morbidity Statistics from General Practice 1991-92. London. U.K: HMSO; 1995.

26. Bhattacharya N, Stubblefield P. Regenerative Medicine using Pregnancyspecific biological substances, Clinical use of Amniotic Fluid in Osteoarthritis: A source of Cell Therapy by Niranjan Bhattacharya. Springer-Verlag London Limited. 2009; 38: 395-400.

27. Bhattacharya N, Clinical Use of Amniotic Fluid in Osteoarthritis: A Source of Cell Therapy. Transplantation 90 January 2011.

28. Pruit $B A$, Lindberg RB. Pseudomonas aeruginosin infection in burn patients. In: Doggett RG, editor. Pseudomonas aeruginosin: clinical manifestations of infection and current therapy. New York: Academic. 1979; 339-66. 